\title{
Design and Comparative Analysis of Small Modular Reactors for Nuclear Marine Propulsion of a Ship
}

\author{
Monirul Hoque1, A. Z. M. Salauddin', Md. Reaz Hasan Khondoker² \\ ${ }^{1}$ Department of Nuclear Science and Engineering, Military Institute of Science and Technology, Dhaka, Bangladesh \\ ${ }^{2}$ Department of Naval Architecture \& Marine Engineering, Military Institute of Science \& Technology, Dhaka, Bangladesh \\ Email: capt.mhoq@gmail.com
}

How to cite this paper: Hoque, M., Salauddin, A.Z.M. and Khondoker, M.R.H. (2018) Design and Comparative Analysis of Small Modular Reactors for Nuclear Marine Propulsion of a Ship. World Journal of Nuclear Science and Technology, 8, 136-145. https://doi.org/10.4236/wjnst.2018.83012

Received: June 15, 2018

Accepted: July 13, 2018

Published: July 16, 2018

Copyright $\odot 2018$ by authors and Scientific Research Publishing Inc. This work is licensed under the Creative Commons Attribution International License (CC BY 4.0).

http://creativecommons.org/licenses/by/4.0/

\begin{abstract}
The fast growth in the size and difficulty of nuclear power plant in the 1970s produced an interest in smaller, modest designs that are intrinsically safe over the usage of design features. With the development of nuclear technology, there is the need for revolution in the Maritime sector, especially the advance marine propulsion. In current years, numerous reactor manufacturers are dynamically improving small modular reactor designs with even superior use of safety features. Several designs integrate the ultimate in greater safety. They totally remove specific accident initiators from the design. Other design features benefit to reduce different types of accident or help to mitigate the accident's consequences. Although some safety features are mutual to maximum SMR designs, irrespective of the coolant technology, other features are specific to liquid-metal cooled, water, gas, or SMR designs. Results: There have been more reactor concepts investigated in the marine propulsion area by different assemblies and research laboratories than in the power generation field, and much can be learned from their experience for land applications. The extensive use of safety features in SMRs potential to make these power plants extremely vigorous, protecting both the public and the investor. Conclusion: For these two considerations, it is recognized that a nuclear reactor is the ideal engine for naval advanced propulsion. The paper will present the work to analyze the concept design of SMRs and design a modular vessel consisting of a propulsion module.
\end{abstract}

\section{Keywords}

Design Analysis, Small Modular Reactor (SMR), Marine Propulsion, Nuclear Ship 


\section{Introduction}

The growing demand for economical yet rapid program of mutually customers and merchandise has carried renewed momentum to the development of marine propulsion systems. New-fangled technologies are aiding the production of propulsion systems that are capable of driving vessels at advanced speeds; that are more efficient; that provide improved maneuverability; and that are quieter, with less vibration. Here, the latest developments in marine propulsion are carried into focus [1]. The main experience in operating nuclear power plants has been in nuclear naval propulsion, mainly aircraft carriers and submarines. This composed experience may become the basis of a proposed new generation of compact-sized nuclear power plants designs. This paper discovers nuclear propulsion by means of a case study, which sets the issues against accurate technical background. The probable use of developing Small Modular Reactor (SMR) nuclear technology onboard sea-going ships opens up new opportunities and this technology forms the base of the study reported [2].

The greatest suited idea for the modular ship is discussed including a review of tug/barge schemes. At present, there is growing interest in small modular reactors (SMRs) and their perfect applications. SMRs are newer generation reactors designed to produce electric power up to $300 \mathrm{MW}$, whose components and systems can be shop fabricated and then transported as modules to the sites for installation as demand arises. Most of the SMR designs approve advanced or even intrinsic safety features and are deployable either as a single or multi-module plant. SMRs are under development for all principal reactor outlines: water cooled reactors, high temperature gas cooled reactors, liquid-metal, sodium and gas-cooled reactors with fast neutron spectrum, and molten salt reactors. The key driving forces of SMR development are fulfilling the need for flexible power generation for a wider range of users and applications, substituting ageing fossil-fired units, attractive safety performance, and contributing better economic affordability. Near term deployable SMRs will have safety performance better to that of evolutionary reactor designs. However, important developments have been made in various SMR technologies in recent years, and some technical issues still attract considerable attention in the industry. These include for example control room staffing and human factor engineering for multi-module SMR plants, defining the source term for multi-module SMR plants with regards to defining the emergency planning zone, developing new codes and standards. Some potential advantages of SMRs like the elimination of public removal during an accident or a single operator for multiple modules are being challenged by regulators. Besides, although SMRs have lower upfront capital cost per unit, their producing cost of electricity will possibly be substantially higher than that for large reactors [3] (Table 1).

An energy absorption-based analysis is mandatory for the structural design in way of the engine room. In this way, during the impact, the energy will be dissolute through the hull and away from the reactor compartment by an 
Table 1. Status of deployment of SMR designs and technologies (partial).

\begin{tabular}{|c|c|c|c|c|c|}
\hline Design & Output & Type & Designers & Country & Status \\
\hline KLT-40S & 70 & Floating NPP & OKBM Afrikantov & Russian Federation & $\begin{array}{c}\text { Under } \\
\text { construction }\end{array}$ \\
\hline HTR-PM & 210 & HTGR & INET, Tsinghua University & China & $\begin{array}{c}\text { Under } \\
\text { construction }\end{array}$ \\
\hline CAREM & 30 & PWR & CNEA & Argentina & $\begin{array}{c}\text { Under } \\
\text { construction }\end{array}$ \\
\hline ACP100 & 100 & PWR & $\mathrm{CNNC}$ & China & $\begin{array}{c}\text { Conceptual } \\
\text { Design }\end{array}$ \\
\hline CAP150/200 & $150 / 200$ & PWR & CGNPC & China & $\begin{array}{c}\text { Conceptual } \\
\text { Design }\end{array}$ \\
\hline AHWR-300 & 300 & PHWR & BARC & India & $\begin{array}{c}\text { Conceptual } \\
\text { Design }\end{array}$ \\
\hline IRIS & 335 & PWR & IRIS Consortium & Multi Countries & $\begin{array}{c}\text { Conceptual } \\
\text { Design }\end{array}$ \\
\hline DMS & 300 & BWR & Hitachi GE & Japan & $\begin{array}{c}\text { Conceptual } \\
\text { Design }\end{array}$ \\
\hline IMR & 350 & PWR & MHI & Japan & $\begin{array}{c}\text { Conceptual } \\
\text { Design }\end{array}$ \\
\hline IMSR & $185-192$ & MSR & Terrestrial Energy & Canada & $\begin{array}{c}\text { Conceptual } \\
\text { Design }\end{array}$ \\
\hline MSTW & 100 & MSR & Seaborg Technologies & Denmark & $\begin{array}{c}\text { Conceptual } \\
\text { Design }\end{array}$ \\
\hline ThorCon & 250 & MSR & Martingale & $\begin{array}{l}\text { International } \\
\text { Consortium }\end{array}$ & $\begin{array}{c}\text { Conceptual } \\
\text { Design }\end{array}$ \\
\hline
\end{tabular}

Source: IAEA, 2016.

elastoplastic collapse. In the ship Otto Hahn, this was achieved through cutting decks which would cut any object colliding into it, thus reducing impact penetration [4]. Another option is provided by sandwich material consisting of "Y" shaped frames which has proven energy absorption due to its plastic collapse [5].

\section{Materials and Methods}

\subsection{Reactor Design Concepts}

There have been extra reactor concepts examined in the maritime propulsion area by different producers and research laboratory than in the private citizen field, and much can be learned from their experience for land applications, mainly for small compact schemes. 


\subsection{Reactor Design Comparison}

The reactor comparison will be based on the below constrains. The first and important is the burn-up. The second constraint is the thermal to electrical efficiency. This efficiency comprises the steam generator efficiency and the electric generator efficiency which differs according to the load. PWR designs work at the temperature range around $320^{\circ} \mathrm{C}$ and 155 bar pressure with a temperature drop like to $30^{\circ} \mathrm{C}$ and 9 bar pressure drop because of the process of the secondary steam cycle. Table 2 covers a comparison of naval reactor designs in overall.

\subsection{Small Modular Reactors (SMR)}

SMRs deliver improvements in safety, construction, operational flexibility and economics. The enhancement in safety is achieved through lower fuel inventory, greater use of safety features and eliminating design features which are disposed to probable accidents [8] and since the SMR is built modularly, the proliferation risk is significantly reduced [9]. Upon authorizing SMRs are expected to have economy of mass production, reduced siting costs and majority of construction and assembly to be completed at the factory thus reducing capital cost and assembly time hence reducing financial risk [10].

Hyperion offers a liquid metal cooled, fast reactor with a thermal power of 70 $\mathrm{MW}_{\mathrm{T}}$. The efficiency of the transfer heat system using helium can be up to $40 \%$. The size of the sealed unit is only $1.5 \mathrm{~m}$ in diameter and $2.5 \mathrm{~m}$ high with a cost of $\$ 50$ million USD [11]. Some other properties of the reactor are given in Table 3 [12].

\section{Result and Discussions}

\subsection{Design Analysis}

A matrix was used to find out the best performing SMR concept. A set of

Table 2. Characteristics of civil reactor designs [6] [7].

\begin{tabular}{|c|c|c|c|c|}
\hline Reactor & PWR & BWR & MAGNOX & AGR \\
\hline Fuel: & 3\% LEU & 2.2\% LEU & Natural Uranium & $2 \% \mathrm{LE} \mathrm{UO}_{2}$ \\
\hline Cladding & Zircalloy & Zircalloy & Magnesium alloy & St. Steel \\
\hline Moderator & Light Water & Light Water & Graphite & Graphite \\
\hline Coolant & Light Water & Light Water & Carbon dioxide & Carbon Dioxide \\
\hline Outlet Temp. & 318 & 318 & 360 & 620 \\
\hline Steam Temp. & 285 & 286 & $\begin{array}{l}345 \mathrm{HP} \\
330 \mathrm{LP}\end{array}$ & 540 \\
\hline Steam Pressure & 69 & 75 & 150 & $\begin{array}{l}40 \mathrm{HP} \\
11 \mathrm{LP}\end{array}$ \\
\hline Efficiency & $32 \%$ & $32 \%$ & $33 \%$ & $42 \%$ \\
\hline Power Density & High & High & Low & Low \\
\hline Burn-up & High & High & Low & Low \\
\hline
\end{tabular}


fundamental criteria were established each with differing importance. For each concept a subjective score between 1 and 5 was assigned for each criterion ( 1 negative or challenging, 5 positive or practicable).

In Figure 1 and Figure 2: Concept 1 complicated taking a conventional containership and separating it into two parts while keeping the same hullform. The aft end of the vessel converts the propulsion unit and the remains of the ship is the cargo unit.

Subsequently Concept 2 was established to clarify the problems by altering the hullform to one consuming podded propulsors that would have a much fuller form and advanced block constant. The similar coupling mechanism as that for Concept 1 is used.

Subsequently Concept 3 was considered to improve these loads. Concept 3 has a propulsion module that submerges and slots into a space in the aft end of the cargo module and is combined by hydraulic arms from the sides, roof and front of the propulsion module.

Table 3. Hyperion SMR characteristics.

\begin{tabular}{cc}
\hline $\begin{array}{c}\text { Electrical output } \\
\text { Lifetime }\end{array}$ & $25 \mathrm{MWE}$ \\
Weight & $8-10$ years \\
Less than 50 tons including pressure vessel, fuel and primary coolant \\
Coolant & Stainless steel \\
Fuel & Lead-Bismuth \\
Enrichment & Stainless clad, uranium nitride \\
\end{tabular}

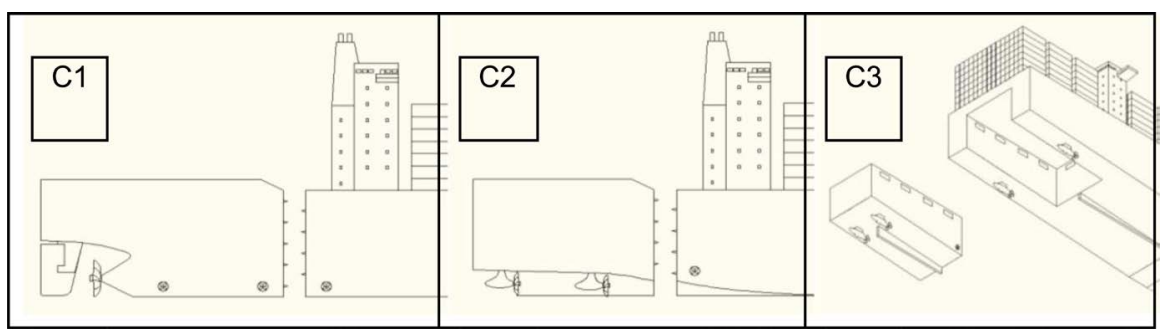

Figure 1. Concepts 1, 2 and 3 [13].

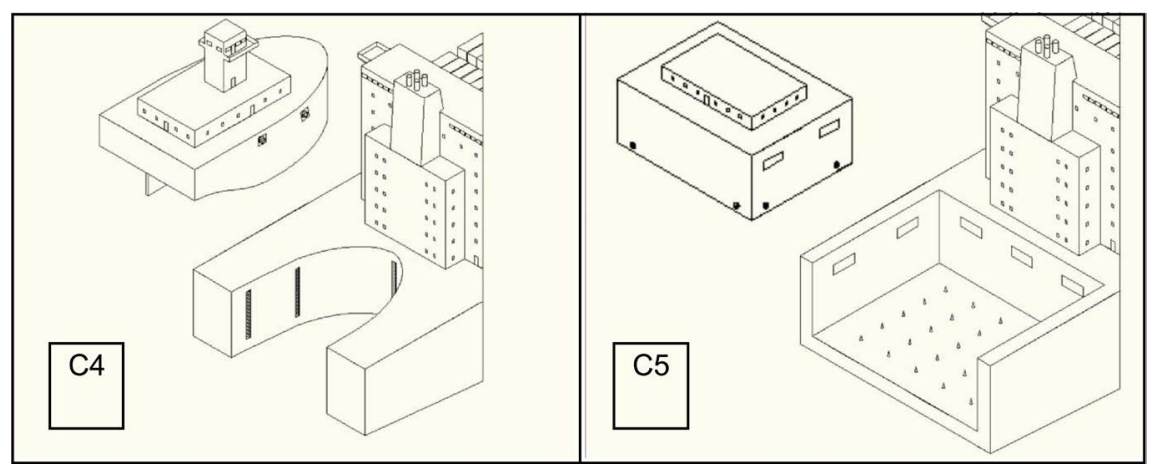

Figure 2. Concepts 4 and 5. 
Concept 4 is like Concept 3 however removes the need to submerge by using the model of a barge system with a mechanically inflexible connection.

Concept 5 attempted to remove these coupling loads completely.

The results are as in Table 4 . Concept 4, a barge system was the best performing and was therefore selected for further development.

\subsection{Design Comparisons (Based on Three)}

Light water reactors are the most common type of nuclear reactor around the world, in which light water is used as a moderator as well as the cooling medium. Uranium fuel is enriched to maintain the criticality of the reactor along entire fuel cycle. As the technology of LWR is already moderately mature and broadly adopted, the LWR SMR designs have their inherited advantages and are expected to be commercialized sooner than all other types of reactors. This low enrichment, along with the technological readiness of LWR, will significantly reduce the expected duration for licensing those SMRs. PWR reactors are easier to operate from a stability standpoint; it also has a lower cost for operation. The economic benefits due to technical matureness, easiness of licensing and the lower operational costs make PWR SMRs attractive to vendors and investors. Together HTGRs and fast neutron reactors are hypothesized more recently. Though more interesting and attractive, they also have much more difficulties and uncertainties than the traditional LWR designs. HTGR reactors normally use gases like carbon dioxide or helium as coolant and graphite as the moderator. Consequently, the graphite-composed core will have a huge heat capacity and structural constancy even at high temperatures. The coated fuel also allows high burn-up and retains fission products. However, the concepts of HTGR are still quite new; thus the costs for licensing, construction and operation will be higher. Among the four fast reactors, there is one gas-cooled and three liquid-metal-cooled fast reactors. Fast reactors differ from thermal reactors as they use fast neutrons to sustain the fission chain reaction, and thus do not need a neutron moderator. Also producing less waste, fast reactors also need less

Table 4. Concept decision matrix.

\begin{tabular}{cccccccc}
\hline \multirow{2}{*}{ Concept Criteria } & Importance & \multicolumn{5}{c}{ Alternative Concepts } \\
\cline { 3 - 7 } & & C 1 & C 2 & C 3 & C 4 & C 5 \\
\hline Module Design & 17.5 & 1 & 1 & 2 & 4 & 3 \\
Propulsion & 10 & 5 & 4 & 3 & 3 & 4 \\
Coupling system & 20 & 1 & 1 & 4 & 4 & 5 \\
Coupling forces & 20 & 2 & 2 & 4 & 4 & 5 \\
Coupling mechanism & 20 & 1 & 1 & 2 & 5 & 4 \\
Application to different vessels & 10 & 2 & 2 & 2 & 5 & 1 \\
Cable power connection & 2.5 & 5 & 5 & 3 & 2 & 5 \\
Total & 100 & 1.8 & 1.7 & 2.93 & 4.15 & 3.95 \\
\hline
\end{tabular}


uranium fuel, as they permit nuclear fuels to be bred from almost all the actinides, including abundant sources of depleted uranium and thorium, and wastes from conventional light water reactors. This "breed and burn" process gives fast reactors a much larger efficiency as compared to other type reactors.

Nevertheless, several obstacles need to be conquered to promote the use of fast reactors. Firstly, critical mass in a fast reactor is much higher than in a thermal reactor because of the low cross sections of most materials at high neutron energies. As a result, significantly higher enrichment is normally necessary for the reactor; uranium fuels are enriched up to $20 \%$ (45). The high enrichment induces a somewhat greater proliferation risk. Fast reactors are also more expensive to build and operate comparing to LWRs. After each cycle, nuclear fuel will be moved from the core to be replaced by new fuel. According to researches, the heavy metal compositions for a typical light water reactor in US before and after running for three years are: uranium dropping from $100 \%$ to $~ 93.4 \%$; from $4.2 \%$ enrichment to $0.71 \%$; plutonium rising from $0 \%$ to $1.27 \%$; minor actinide from $0 \%$ to $0.14 \%$ and fission products from $0 \%$ to $5.15 \%$ (Figure 3 ).

Among the three reactor classes, fast neutron reactors have the highest fuel efficiency although producing least radiotoxic wastes. Fast reactors allow fully exploiting the energy potential of uranium fuels by converting the fertile U-238 in

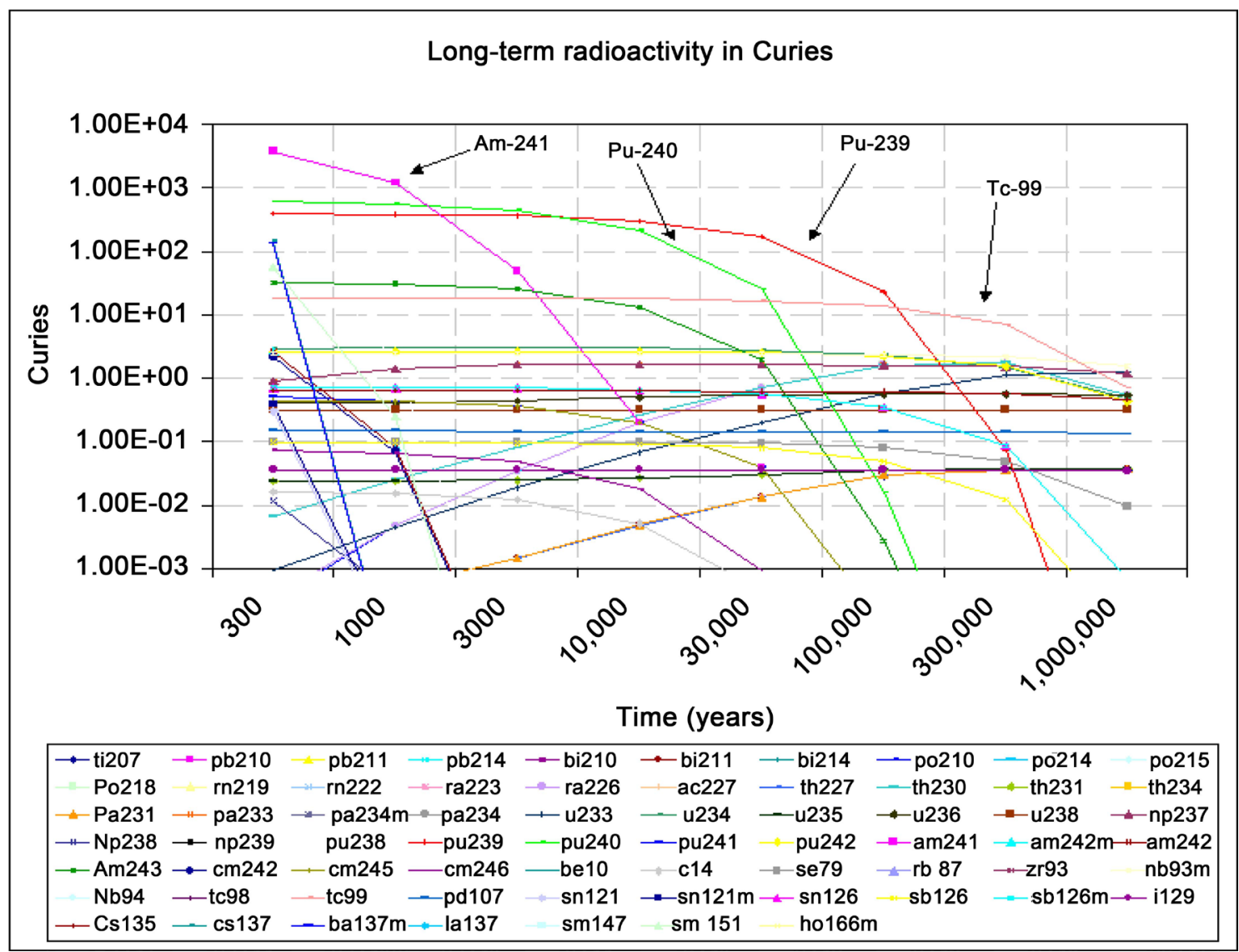

Figure 3. The long-term activity of all the radioactive nuclides burnt to $45 \mathrm{MWd} / \mathrm{kg}$. Data as computed by https://whatisnuclear.com/ [14]. 
the wastes to fissile $\mathrm{Pu}-239$ and reusing the fissile materials; thus, they can extract sixty-to-seventy times more energy from uranium than thermal reactors do. A higher efficiency means a smaller input required, for producing the same amount of energy. On the other hand, researches have indicated that actinides tend to have a higher probability of fission at fast energies, so fast reactors can burn more efficiently the long life transuranic wastes and significantly reducing the activity and the required isolation time of the nuclear wastes. Since these three factors above, it seems genuine to put the four fast neutron spectrum reactors as best candidates for the study.

\subsection{Calculations of the Nuclear Propulsion System}

The submarine nuclear propulsion system includes steam turbines, to which the steam is delivered from the cooling system of the reactor. Nowadays almost all nuclear submarines are equipped with two-contour nuclear cycles cooled with light water, of PWR type. The steam generated in the steam generator is most frequently delivered to two turbines (turbo generator and the main turbine, see Figure 4). The calculations of a typical cycle of a two-contour nuclear power plant with steam separation and live steam interstage superheating were done. In this system the live steam parameters were equal to: pressure-7MPa, temperature $-285.8^{\circ} \mathrm{C}([9])$, while the division pressure was optimized to obtain 1.05 $\mathrm{MPa}$ for the degree of dryness equal to 0.85 (end of expansion in the HP part). Internal efficiencies of the turbines were assumed at the level of $90 \%$ while the pressure in the condenser was assumed equal to $6 \mathrm{kPa}$. The assumed power output of the turbine was equal to $70 \mathrm{MW}$ (large nuclear submarine). The gross efficiency (neglecting boat's own needs) of this cycle was equal to $32.1 \%$. The mass flow rate was $90.14 \mathrm{~kg} / \mathrm{s}$. Revolutions of the high-pressure part were set at the level of $4800 \mathrm{rev} / \mathrm{min}$ while for the low-pressure part: $2000 \mathrm{rev} / \mathrm{min}$. Preliminary thermodynamic and flow calculations have made the basis for designing the

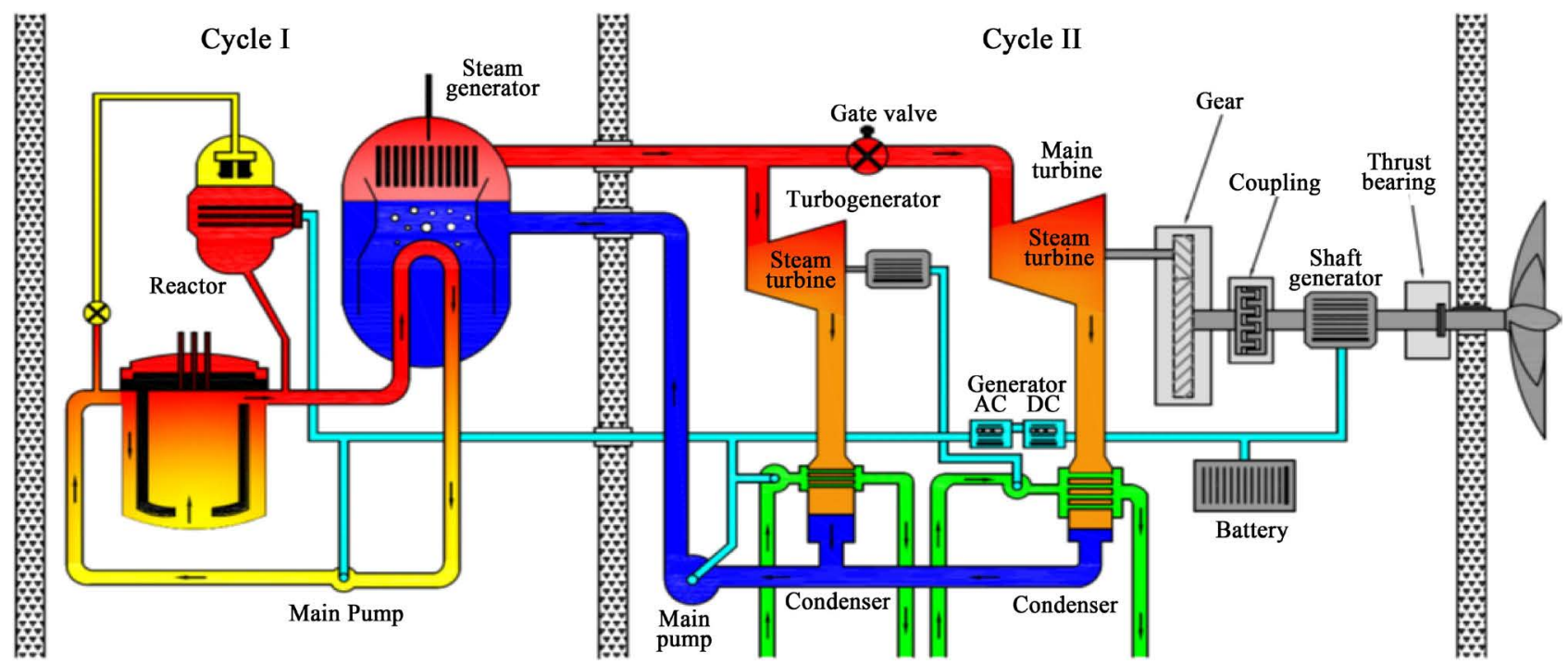

Figure 4. Simplified scheme of nuclear propulsion system in two-contour PWR cycle [15]. 
flow paths of the high-pressure turbine part and the low-pressure part (see Figure 4). The high-pressure part had six stages having circumferential efficiency not exceeding $90 \%$, while in the low-pressure part 7 stages were obtained with circumferential efficiency over $90 \%$.

\section{Conclusions}

As nuclear-powered ship is wide-ranging high powered, container ships and icebreaking vessels are appropriate for initial implementation of nuclear propulsion. Growing nuclear propulsion to other ship types, such as slower-going bulk carriers, will generally require higher service speeds than the traditional fossil fuel ship. The success of nuclear propulsion finally is tied to the success of nuclear fission in general. Absorbed opposition will be faced from the hydrocarbon and renewable energy industries, and any other lucrative industries which stand to lose out from the acceptance and widespread use of nuclear energy. The Nuclear Marine Propulsion system is a mainly energy system that consumes nuclear fuel for energy ensuing in heat, while to produce mechanical energy or output power essential to turn the propeller used steam turbine. Nuclear marine reactors consume a maximum level of burn-up fuels, for example, uranium-zirconium, uranium-aluminum, and metal ceramic fuels. On the other hand, land-based reactors consume uranium dioxide UO2. These factors deliver the naval vessels theoretical infinite range and mission time. For these two considerations, it is recognized that a nuclear reactor is the perfect engine for nuclear marine propulsion.

\section{References}

[1] Martines, I. (1995) Marine Propulsion. USA.

[2] Ragheb, M. (1982) Lecture Notes on Fission Reactors Design Theory. FSL-33, University of Illinois, USA.

[3] SMR-Book. (2016) IAEA Advanced Reactors Information System (ARIS). http://aris.iaea.org

[4] Jacobs, J.G.C.C. (2007) Nuclear Short Sea Shipping. M.Sc., Delft University of Technology, Delft.

[5] Pedersen, C.B.W., Deshpande, V.S. and Fleck, N.A. (2006) Compressive Response of the Y-Shaped Sandwich Core. European Journal of Mechanics A/Solids, 25, 125-141. https://doi.org/10.1016/j.euromechsol.2005.06.001

[6] HMS-Sultan (2008) Sustainable Energy Nuclear Power. Lecture Notes SESG6026, MSc, University of Southampton, HMS Sultan, Nuclear Department Defence Academy.

[7] Pocock, R. (1970 Nuclear Ship Propulsion. Ian Allan.

[8] Ingersoll, D.T. (2009) Deliberately Small Reactors and the Second Nuclear Era. Progress in Nuclear Energy, 51, 589-603.

https://doi.org/10.1016/j.pnucene.2009.01.003

[9] Mackay, M. (2011) Critical Evaluation of MIRIS and Hyperion SMRs for Use in a Vista Class Cruise Liner. HMS SULTAN: Defence College of Management and Technology. 
[10] Hirdaris, S.E. and Cheng, F. (2012) The Role of Technology in Green Ship Design. 11 th International Marine Design Conference, Glasgow, 11-14 June 2012, 19-40.

[11] Dabrowska, D., Macchesney, R.S., Padden, T., Pugh, G. and Symonette, A. (2012) Installation of Nuclear Power on a Double Acting LNG Carrier. University of Southampton, Southampton.

[12] Hirdaris, S.E., Cheng, F., Jenkins, V., Bonafoux, J., Shallcross, P., Andrew, W., Peterson, O.P., Govers, R., Deal, J.G., Rich, K. and Lucas, D. (2011) Concept Design of a Suez Max Tanker Propelled by a Small Modular Reactor-Some Preliminary Considerations. The 1 st Global Forum on Structural Longevity, Orlando, 18-19 March 2014,41 .

[13] Gravina, J. (2011) Structural Analysis and Loads for a Modular Nuclear Merchant Ship: 12 Month Report. University of Southampton, Southampton.

[14] https://whatisnuclear.com/articles/waste.html

[15] https://fas.org/man/dod-101/sys/ship/eng/reactor.html 